\title{
Lack of association between five serotonin metabolism-related genes and medication overuse headache
}

\author{
Sabina Cevoli • Nadia Marzocchi · Sabina Capellari • Chiara Scapoli • \\ Giulia Pierangeli • Daniela Grimaldi · Federica Naldi • L. Alberto Pini · \\ Pasquale Montagna $\cdot$ Pietro Cortelli
}

Received: 24 September 2009/Accepted: 22 October 2009/Published online: 21 November 2009

(c) Springer-Verlag 2009

\begin{abstract}
Serotonin is involved in several central nervous system functions including pain threshold, mood regulation and drug reward. Overuse of acute medications is commonly identified as a causative factor for medication overuse headache $(\mathrm{MOH})$. Apparently, $\mathrm{MOH}$ shares with other kinds of drug addiction some common neurobiological pathways. The objective of this study is to assess the role of serotonin metabolism genes in the genetic liability to $\mathrm{MOH}$. We performed a genetic association study using polymorphisms of five serotonin metabolism-related genes: serotonin transporter $(5 H T T)$, serotonin receptor $1 \mathrm{~A}$ (5-HT1A), serotonin receptor $1 \mathrm{~B}(5-H T 1 B)$, serotonin receptor $2 \mathrm{~A}(5-H T 2 A)$ and serotonin receptor 6 (5HT6) genes. We compared 138 patients with $\mathrm{MOH}$ with a control sample of 117 individuals without headache and without drug overuse, and with 101 patients with migraine without aura but without drug overuse (MO). The genotypic and allelic distributions of all polymorphisms investigated did not differ among the three groups. In conclusion, our study does not provide evidence that the 5HTT, 5-HT1A, 5HT1B, $5 H T 2 A$ and $5 H T 6$ gene polymorphisms play a role in the genetic predisposition to $\mathrm{MOH}$.
\end{abstract}

S. Cevoli $(\bowtie)$ - S. Capellari · G. Pierangeli · D. Grimaldi ·

F. Naldi · P. Montagna · P. Cortelli

Department of Neurological Sciences,

University of Bologna Medical School,

Via U. Foscolo 7, 40123 Bologna, Italy

e-mail: sabina.cevoli@unibo.it

N. Marzocchi · L. Alberto Pini

Headache Centre, University of Modena

and Reggio Emilia, Modena, Italy

C. Scapoli

Department of Biology and Evolution,

University of Ferrara, Ferrara, Italy
Keywords Chronic headache - Drug overuse · Medication overuse headache · Polymorphism · Serotonin · Genetic

\section{Introduction}

Chronic headache $(\mathrm{CH})$, a group of headaches occurring daily or almost daily, is a major clinical concern and a common health risk. Overuse of acute medications, being present in more than $80 \%$ of $\mathrm{CH}$ patients seen in tertiary headache centres, is commonly identified as the most important risk factors for $\mathrm{CH}$ and a causative factor for medication overuse headache (MOH) [1].

Apparently, MOH shares with other kinds of drug addiction some common neurobiological pathways, including those that modulate reward, novelty seeking, behavioural control and response to stress [2]. Liability to drug dependence has been traced to polymorphisms in genes regulating monoaminergic transmission [3]. In particular, several serotonin metabolism-related polymorphisms have been associated with addiction, psychiatric disorders and migraine headache.

Few studies have focused on the genetics of CHs. Russell et al. [4] found that first-degree relatives of probands with chronic tension-type headache (CTTH) had a 2.1- to 3.9-fold significantly increased risk of CTTH with respect to the general population. We found that $\mathrm{CH}$ sufferers had significantly higher positive family history for $\mathrm{CH}$ compared to episodic headache sufferers. In particular, patients with $\mathrm{CH}$ associated with drug overuse had more frequently family history of drug overuse and substance abuse [5]. The significantly increased familial risk for $\mathrm{CH}$, drug overuse and substance abuse suggests that genetic factors are involved in the process of headache chronification. 
Homozygosis for the short allele of the 5-HTTLPR $(S / S$ genotype), a polymorphism in the serotonin transporter gene regulatory region, has been found to be associated with an increased frequency of attacks in migraine patients compared with those with $l / S$ or $l / l$ genotype [6]. Park et al. [7] studied patients with CTTH with and without analgesic overuse, demonstrating an excess frequency of the 5-HTTLPR short allele (S/S genotype) in the analgesic overuse group. We performed a genetic association study of serotonin metabolism-related genes in three population groups: one affected with $\mathrm{MOH}$, one with episodic migraine without aura and without drug abuse (MO) and one control population without headache and without drug abuse.

We analysed polymorphisms in five serotonin metabolism-related genes: the serotonin transporter (5HTT), serotonin receptor $1 \mathrm{~A}(5-H T 1 A)$, serotonin receptor $1 \mathrm{~B}$ $(5-H T 1 B)$, serotonin receptor $2 \mathrm{~A}(5-H T 2 A)$ and serotonin receptor 6 (5HT6) genes. The 5HTT gene codes for a protein responsible for the reuptake of serotonin from the extracellular space and has an important role in determining the magnitude and duration of serotonin activity on its pre- and post-synaptic receptors. The 5-HT1A, 5HT1B, $5 H T 2 A$ and $5 H T 6$ genes code for different serotonin receptors.

\section{Patient and methods}

Description of analysed populations

A total of 138 unrelated patients affected with $\mathrm{MOH}$ aged 22-81 were compared with a control population of 117 unrelated individuals without headache and without drug overuse, and to a population of 101 patients with episodic migraine without aura without drug overuse (MO). All patients were referred to the Neurological Department of the University of Bologna and to the Headache Centre of the University of Modena and Reggio-Emilia, two Italian tertiary Headache Centres. To reduce stratification bias, the populations studied came from the same region in North-Eastern Italy, Emilia-Romagna, and all were of Caucasian origin. The control population was composed of healthy laboratory staff and neurological patients without migraine. All controls and MO individual had to be over age 40 , in order to reduce ascertainment bias related to age of onset of migraine headache. The institutional review board of the Department of Neurological Sciences of the University of Bologna Medical School approved the project and each patient gave informed consent to the study.

All patients and normal subjects were diagnosed by headache expert physician after direct interview according to the revised diagnostic criteria of the International Headache Society classification (ICHD-II) [8]. At the time of the visit a headache specialist performed a semi-structured history-taking interview and a neurological examination. Patients were asked about headache characteristics at onset and at the time of the inclusion in the study. Headache frequency and drug overuse were evaluated by means of headache diaries filled in for at least 3 months previous to inclusion. All patients and controls were investigated about family history for headache and for substance abuse. Substance use disorders and comorbidity for mood and anxiety disorders were diagnosed by mean of semi-structured interviews by trained doctors and reported according to Axis I of the DSM-IV criteria.

\section{Genetic analysis}

We studied the following DNA polymorphisms: a variable number of tandem repeats (VNTR) of 17-base-pair (bp) repeats located in the second intron of 5HTT localised on chromosome 17q12 (STin 2 polymorphism: STin 2.8, STin 2.9, STin 2.10, STin 2.11, STin 2.12) [9]; a transition $\mathrm{A} \rightarrow \mathrm{G}$ at nucleotide 82 of 5-HT1A located on chromosome 5q11.2-q13, which leads to an amino acid exchange (Ile $\rightarrow$ Val) in position 28 of the receptor protein [10]; a $\mathrm{T} \rightarrow \mathrm{C}$ transition in position 102 in exon 1 of $5-H T 2 A$ that does not alter the amino acid composition (chromosome 13q14-21) [11]; a silent $\mathrm{G} \rightarrow \mathrm{C}$ substitution at position 861 in the coding sequence, and a $\mathrm{T} \rightarrow \mathrm{G}$ transition at position -261 of 5-HT1B (chromosome 6q13-q15) [12], and a silent $\mathrm{C} \rightarrow \mathrm{T}$ transition in position 267 of the coding region of the 5HT6 localised in 1p35-36 [13].

Molecular techniques for DNA extraction and amplification were those previously reported [14]. Due to technical difficulties (DNA exhaustion, PCR failure), the number of individuals examined in the different samples varied (see tables).

\section{Statistical analysis}

Chi-square analysis was used to test for deviations of genotype frequencies from Hardy-Weinberg expectations for both biallelic systems and STin 2 polymorphism for which only three alleles have been observed in our sample (STin 2.8, STin 2.9 and STin 2.12). Genotypic and allelic frequencies among the different groups were compared using the log-linear analysis for categorical data in twodimensional tables or Fisher's exact test. The test of nonrandom association of alleles at different loci (linkage disequilibrium estimate) was performed by Arlequin Software, Ver 3.0. Multivariate logistic regression was used to test for interaction between polymorphisms. The level of significance was chosen as $P<0.05$. When necessary, 
$P$ values were subject to Bonferroni's correction for multiple comparisons.

\section{Results}

Clinical features of $\mathrm{MOH}$ patients are reported in Table 1. All the polymorphisms analysed were in HardyWeinberg equilibrium except for the STin 2 polymorphism in the MOH group $\left(\chi^{2}=10.03, P=0.018\right)$. The $5 H T 1 B$ (G861C) was in linkage disequilibrium with the 5-HT1B $(C-261 T)$ polymorphism $\left(\chi^{2}=19.70, P=0.00057\right)$.

The genotypic and allelic distributions of SNPs at the $5 H T 1 B, 5 H T 2 A$ and STin 2 in 5HTT did not differ among the three groups at the exact test of population differentiation as shown in Tables 2, 3 and 4.

Concerning the 5HT1A (A82G) polymorphism we found an indication of a genetic difference in the $\mathrm{MOH}$ compared

Table 1 Demographic data of MOH patients $(n=138,19 \mathrm{M} / 119 \mathrm{~F}$, 22-81 years)

\begin{tabular}{lc}
\hline & $N(\%)$ \\
\hline Clinical features & \\
Smokers & $38(27.5 \%)$ \\
Ex-smokers & $4(8.7 \%)$ \\
Familiarity for headache & $107(77.5 \%)$ \\
First-grade parent with headache & $103(74.6 \%)$ \\
Familiarity for drug/alcohol abuse (tot.) & $40(32.6 \%)$ \\
Parents with headache and analgesic overuse & $33(23.9 \%)$ \\
Parents with alcohol abuse & $11(7.9 \%)$ \\
Parents with drug addiction (opioid) & $2(1.4 \%)$ \\
Parents with anxiolytic abuse & $1(0.7 \%)$ \\
Anxiety/depression comorbidity (tot.) & $56(40.5 \%)$ \\
Depression & $47(34 \%)$ \\
Anxiety & $42(30.4 \%)$ \\
Anxiety and depression co-presence & $33(23.9 \%)$ \\
Headache drug overused & \\
Abuse of combination analgesics & $91(65.9 \%)$ \\
Combination with indomethacin and caffeine & $41(29.7 \%)$ \\
Combination with barbiturate & $37(26.8 \%)$ \\
Combination with ergotamine & $8(5.8 \%)$ \\
Combination with NSAIDs and caffeine & $3(2.2 \%)$ \\
Combination with opioid & $2(1.4 \%)$ \\
Triptans & $49(35.5 \%)$ \\
NSAIDs & $40(29 \%)$ \\
Acetaminophen & $5(3.6 \%)$ \\
Metamizole & $2(1.4 \%)$ \\
Overuse of one drug & $68(49.3 \%)$ \\
\hline & $66(47.8 \%)$ \\
\hline
\end{tabular}

to the MO group both for genotypic and for allelic distribution ( $P=0.039$ and $P=0.049$, respectively) mainly as a result of an under-representation of allele $G$ in the $\mathrm{MOH}$ group (Table 5). However, the results were not significant after the Bonferroni's correction.

For the $(C 267 T)$ polymorphism in the 5HT6 receptor gene, we found a significant allelic difference in $\mathrm{MOH}$ compared with control group $(P=0.033)$ mainly because of an overrepresentation of allele $C$ in the $\mathrm{MOH}$ group, but we found no differences between $\mathrm{MO}$ and $\mathrm{MOH}$ (Table 6). In this case too, the $P$ value became non-significant after Bonferroni's correction. A multivariate analysis did not show interactions between the analysed polymorphisms.

\section{Discussion}

In this genetic association study, we analysed polymorphisms of five genes involved in the serotonergic pathways in patients with $\mathrm{CH}$ and drug overuse compared with a control population of individuals without headache and without drug overuse, and to a sample of patients with migraine headache without overuse. As in our previous study [15], these multiple comparisons were meant to search for genetic traits specifically associated with drug overuse in headache patients and to separate these from possibly different liabilities to headache pain.

No differences were found for allelic or genotypic distributions of the polymorphisms at the $5 H T T, 5 H T 1 B$, 5HT2A, 5HT1A and 5HT6 genes. The STin 2 polymorphism was not in Hardy-Weinberg equilibrium in the $\mathrm{MOH}$ group but the size of the samples and its triallelic distribution could account for this finding. The $5 H T 1 B$ $(G 861 C)$ polymorphism was in linkage disequilibrium with the $5-H T 1 B(C-261 T)$ polymorphism, indicating that both alleles are likely part of an extended haplotype.

On the basis of our data, these genes do not seem to be implicated in the genetic liability either to migraine or to $\mathrm{MOH}$. These results confirm our previous negative genetic studies performed in a different set of patients in which we did not found any association between migraine and serotonin metabolism genes [16, 17]. However, to exclude definitively a role of the studied genes in the phenotype of $\mathrm{MOH}$, a larger sample size is recommended.

Previous associations between the $5 H T T$ (STin 2) polymorphism and migraine with and without aura [18, 19] were not confirmed in our population. However, we cannot exclude an involvement of other 5HTT gene polymorphisms, such as the 5-HTTLPR, in the genetic liability to migraine or $\mathrm{MOH}$ as previously reported [6, 7]. However, STin 2 was found to be in linkage disequilibrium with 5 $H T T L P R$ in different populations, and the two polymorphisms have a combined effect on the rate of 5HTT mRNA 
Table 2 Genotypic and allelic frequencies of 5-HT1B polymorphism in controls, migraine without aura and without drug overuse (MO) and medication overuse headache (MOH)

\begin{tabular}{|c|c|c|c|}
\hline & $\begin{array}{l}\text { Controls }(n=104) \\
n(\%)\end{array}$ & $\begin{array}{l}\mathrm{MO}(n=107) \\
\mathrm{n}(\%)\end{array}$ & $\begin{array}{l}\mathrm{MOH}(n=105) \\
\mathrm{n}(\%)\end{array}$ \\
\hline \multicolumn{4}{|c|}{ 5-HT1B (-261) genotype } \\
\hline GG & $21(0.20)$ & $23(0.22)$ & $16(0.15)$ \\
\hline GT & $44(0.42)$ & $44(0.41)$ & $46(0.44)$ \\
\hline TT & $39(0.38)$ & $40(0.37)$ & $43(0.41)$ \\
\hline MO versus controls & $\chi^{2}=0.061(P=0.970)$ & & \\
\hline $\mathrm{MOH}$ versus controls & $\chi^{2}=0.913(P=0.634)$ & & \\
\hline $\mathrm{MOH}$ versus $\mathrm{MO}$ & $\chi^{2}=1.397(P=0.497)$ & & \\
\hline \multicolumn{4}{|l|}{ 5-HT1B alleles } \\
\hline G & $81(0.43)$ & $81(0.42)$ & $119(0.62)$ \\
\hline $\mathrm{T}$ & $105(0.57)$ & $111(0.58)$ & $73(0.38)$ \\
\hline MO versus controls & $\chi^{2}=0.02(P=0.883)$ & & \\
\hline $\mathrm{MOH}$ versus controls & $\chi^{2}=0.77(P=0.379)$ & & \\
\hline \multirow[t]{2}{*}{$\mathrm{MOH}$ versus $\mathrm{MO}$} & $\chi^{2}=1.07(P=0.302)$ & & \\
\hline & $\begin{array}{l}\text { Controls }(n=103) \\
n(\%)\end{array}$ & $\begin{array}{l}\mathrm{MO}(n=110) \\
n(\%)\end{array}$ & $\begin{array}{l}\mathrm{MOH}(n=110) \\
n(\%)\end{array}$ \\
\hline \multicolumn{4}{|l|}{ 5-HT1B (861) genotype } \\
\hline GG & $50(0.48)$ & $57(0.52)$ & $62(0.56)$ \\
\hline GC & $48(0.47)$ & $46(0.42)$ & $44(0.40)$ \\
\hline $\mathrm{CC}$ & $5(0.05)$ & $7(0.06)$ & $4(0.04)$ \\
\hline MO versus controls & $\chi^{2}=0.606(P=0.739)$ & & \\
\hline $\mathrm{MOH}$ versus controls & $\chi^{2}=1.343(P=0.511)$ & & \\
\hline $\mathrm{MOH}$ versus $\mathrm{MO}$ & $\chi^{2}=1.083(P=0.582)$ & & \\
\hline \multicolumn{4}{|l|}{ 5-HT1B alleles } \\
\hline G & $124(0.69)$ & $105(0.68)$ & $114(0.66)$ \\
\hline $\mathrm{C}$ & $56(0.31)$ & $49(0.32)$ & $58(0.34)$ \\
\hline MO versus controls & $\chi^{2}=0.04(P=0.839)$ & & \\
\hline $\mathrm{MOH}$ versus controls & $\chi^{2}=1.13(P=0.288)$ & & \\
\hline MOH versus MO & $\chi^{2}=0.76(P=0.382)$ & & \\
\hline
\end{tabular}

Table 3 Genotypic and allelic frequencies of 5-HT2A polymorphism in controls, migraine without aura and without drug overuse (MO) and medication overuse headache $(\mathrm{MOH})$

\begin{tabular}{llll}
\hline & $\begin{array}{l}\text { Controls }(n=100) \\
n(\%)\end{array}$ & $\begin{array}{l}\text { MO }(n=98) \\
n(\%)\end{array}$ & $\begin{array}{l}\text { MOH }(n=101) \\
n(\%)\end{array}$ \\
\hline 5-HT2A (102) genotype & & $18(0.18)$ & $23(0.23)$ \\
CC & $50(0.50)$ & $53(0.54)$ & $58(0.57)$ \\
CT & $25(0.25)$ & $27(0.28)$ & $20(0.20)$ \\
TT & $\chi^{2}=1.289(P=0.525)$ & & \\
MO versus controls & $\chi^{2}=1.228(P=0.541)$ & & \\
MOH versus controls & $\chi^{2}=1.838(P=0.399)$ & & \\
MOH versus MO & $100(0.50)$ & $89(0.45)$ & \\
5-HT2A alleles & $100(0.50)$ & $109(0.55)$ & \\
C & $\chi^{2}=0.83(P=0.36)$ \\
T & $\chi^{2}=0.09(P=0.766)$ & & \\
MO versus controls & $\chi^{2}=1.47(P=0.226)$ & & \\
MOH versus controls & & & \\
MOH versus MO & &
\end{tabular}


Table 4 Genotypic and allelic frequencies of VNRT-2 polymorphism in controls, migraine without aura and without drug overuse (MO) and medication overuse headache $(\mathrm{MOH})$

\begin{tabular}{llrl}
\hline & $\begin{array}{l}\text { Controls }(n=104) \\
n(\%)\end{array}$ & $\begin{array}{l}\text { MO }(n=86) \\
n(\%)\end{array}$ & $\begin{array}{l}\text { MOH }(n=101) \\
n(\%)\end{array}$ \\
\hline VNRT-2 polymorphism: STin $2.8-2.9-2.12$ genotype & & $3(0.03)$ \\
$8 / 12$ & $3(0.03)$ & $1(0.01)$ & $23(0.23)$ \\
$9 / 9$ & $21(0.20)$ & $17(0.20)$ & $32(0.32)$ \\
$9 / 12$ & $38(0.37)$ & $42(0.49)$ & $42(0.42)$ \\
$12 / 12$ & $41(0.39)$ & $26(0.30)$ & $1(0.01)$ \\
$8 / 9$ & $1(0.01)$ & & \\
MO versus controls & $\chi^{2}=4.734(P=0.316)$ & \\
MOH versus controls & $\chi^{2}=0.574(P=0.966)$ & & \\
MOH versus MO & $\chi^{2}=7.287(P=0.121)$ & & $123(0.019)$ \\
VNRT-2 polymorphism: STin & $2.8-2.9-2.12$ alleles & & \\
8 & $4(0.02)$ & $79(0.44)$ & \\
9 & $81(0.39)$ & $95(0.55)$ & \\
12 & $123(0.60)$ & & \\
MO versus controls & $\chi^{2}=2.28(P=0.320)$ & \\
MOH versus controls & $\chi^{2}=0.01(P=0.998)$ & \\
MOH versus MO & $\chi^{2}=2.27(P=0.321)$ & & \\
\hline
\end{tabular}

Table 5 Genotypic and allelic frequencies of 5-HT1A polymorphism in controls, migraine without aura and without drug overuse (MO) and medication overuse headache $(\mathrm{MOH})$

\begin{tabular}{lllr}
\hline & $\begin{array}{l}\text { Controls } \\
(n=94)\end{array}$ & $\begin{array}{l}\text { MO } \\
(n=96)\end{array}$ & $\begin{array}{l}\text { MOH } \\
(n=99)\end{array}$ \\
\hline 5-HT1A (82) genotype & & \\
AA & $90(0.96)$ & $88(0.92)$ & $97(0.98)$ \\
AG & $4(0.04)$ & $8(0.08)$ & $2(0.002)$ \\
MO versus controls & $\chi^{2}=1.361(P=0.243)$ & \\
MOH versus controls & $\chi^{2}=0.812(P=0.367)$ & \\
MOH versus MO & $\chi^{2}=4.247(P=0.039)^{*}$ & \\
5-HT1A alleles & & \\
A & $184(0.98)$ & $184(0.84)$ & $196(0.99)$ \\
G & $4(0.02)$ & $8(0.04)$ & $2(0.001)$ \\
MO versus controls & $\chi^{2}=1.29(P=0.256)$ & \\
MOH versus controls & $\chi^{2}=0.79(P=0.376)$ & \\
MOH versus MO & $\chi^{2}=3.88(P=0.049)^{*}$ & \\
\hline
\end{tabular}

* Significant at $P \leq 0.05$

transcription [20]. We chose to analyse the STin 2 polymorphism because it seems to influence the gene transcription in an allele-dependent manner and may thus modify neuronal transmission.

In conclusion, our study does not provide evidence that polymorphisms at the $5 H T T, 5-H T 1 A, 5 H T 1 B, 5 H T 2 A$ and $5 H T 6$ genes play a role in the genetic predisposition to $\mathrm{MOH}$. However, we believe that our findings need confirmation in other genetically diverse populations. Genetic association studies are indeed susceptible to false positives
Table 6 Genotypic and allelic frequencies of 5-HT6 polymorphism in controls, migraine without aura and without drug overuse (MO) and medication overuse headache $(\mathrm{MOH})$

\begin{tabular}{|c|c|c|c|}
\hline & $\begin{array}{l}\text { Controls } \\
(n=100)\end{array}$ & $\begin{array}{l}\text { MO } \\
(n=84)\end{array}$ & $\begin{array}{l}\mathrm{MOH} \\
(n=99)\end{array}$ \\
\hline \multicolumn{4}{|l|}{ 5-HT6 (267) genotype } \\
\hline TT & $74(0.74)$ & $55(0.65)$ & $61(0.62)$ \\
\hline $\mathrm{TC}$ & $24(0.24)$ & $26(0.31)$ & $32(0.32)$ \\
\hline $\mathrm{CC}$ & $2(0.02)$ & $3(0.04)$ & $6(0.06)$ \\
\hline MO versus controls & \multicolumn{3}{|c|}{$\chi^{2}=1.697(P=0.428)$} \\
\hline $\mathrm{MOH}$ versus controls & \multicolumn{3}{|c|}{$\chi^{2}=4.489(P=0.106)$} \\
\hline $\mathrm{MOH}$ versus $\mathrm{MO}$ & \multicolumn{3}{|c|}{$\chi^{2}=0.721(P=0.697)$} \\
\hline \multicolumn{4}{|l|}{ 5-HT6 alleles } \\
\hline $\mathrm{T}$ & $172(0.86)$ & $138(0.84)$ & $154(0.77)$ \\
\hline $\mathrm{C}$ & $28(0.14)$ & $26(0.16)$ & $44(0.23)$ \\
\hline MO versus controls & \multicolumn{3}{|c|}{$\chi^{2}=1.70(P=0.192)$} \\
\hline $\mathrm{MOH}$ versus controls & \multicolumn{3}{|c|}{$\chi^{2}=4.53(P=0.033)^{*}$} \\
\hline $\mathrm{MOH}$ versus $\mathrm{MO}$ & \multicolumn{3}{|c|}{$\chi^{2}=0.56(P=0.456)$} \\
\hline
\end{tabular}

* Significant at $P \leq 0.05$

due to genetic population diversity, population structure and to multiple tests performed. In fact, although many claims of associations have been published, the statistical support tended to be weak. For that reason we chose a conservative statistic. Another possible interpretation of our negative results could be that they showed a tendency to an association between the 5HTIA and 5HT6 genes and $\mathrm{MOH}$. In particular, our data could indicate a tendency towards a protective effect of the $\mathrm{G}$ allele of the $5 H T 1 \mathrm{~A}$ gene versus addiction in migraine patients, and an 
overrepresentation of allele $C$ compared of allele $T$ of the $5 H T 6$ gene in $\mathrm{MOH}$ group. However, the statistical significance disappeared after correction for multiple comparisons. If such associations were nonetheless true, our results could be useful for future meta-analyses that could overcome the problem of a low statistical power. Finally, we belive that the putative pathogenetic and therapeutic relevance of the serotoninergic system in $\mathrm{MOH}$ deserves confirmation in other studies on other genes involved in the serotonin metabolism.

Acknowledgments The authors thank Dr Mirella Mochi for her scientific support and Ms Sabrina Farnè for technical assistance.

Conflict of interest statement No conflict of interest.

\section{References}

1. Diener HC, Limmroth V (2004) Medication-overuse headache: a worldwide problem. Lancet Neurol 3:475-483

2. Calabresi P, Cupini ML (2005) Medication-overuse headache: similarities with drug addiction. Trends Pharmacol Sci 26:62-68

3. Goldman D, Oroszi G, Ducci F (2005) The genetics of addictions: uncovering the genes. Nat Rev Genet 6:521-532

4. Russell MB, Ostergaard S, Bendtsen L, Olesen J (1999) Familial occurrence of chronic tension-type headache. Cephalalgia 19:207-210

5. Cevoli S, Sancisi E, Grimaldi D, Pierangeli G, Zanigni S, Nicodemo M, Cortelli P, Montagna P (2009) Family history for chronic headache and drug overuse as a risk factor for headache chronification. Headache 49:412-418

6. Kotani K, Shimomura T, Shimomura F, Ikawa S, Nanba E (2002) A polymorphism in the serotonin transporter gene regulatory region and frequency of migraine attacks. Headache 42:893-895

7. Park JW, Kim JS, Kim YI, Lee KS (2005) Serotonergic activity contributes to analgesic overuse in chronic tension-type headache. Headache 45:1229-1235

8. Headache Classification Committee, Olesen J, Bousser M-G, Diener H-C et al (2006) New appendix criteria open for a broader concept of chronic migraine. Cephalalgia 26:742-746
9. Yilmaz M, Erdal ME, Herken H, Cataloluk O, Barlas O, Bayazit YA (2001) Significance of serotonin transporter gene polymorphism in migraine. J Neurol Sci 186:27-30

10. Serretti A, Lilli R, Lorenzi C, Lattuada E, Smeraldi E (2000) Serotonin-2C and serotonin-1A receptor genes are not associated with psychotic symptomatology of mood disorders. Am J Med Genet 96:161-166

11. Erdal ME, Herken H, Yilmaz M, Bayazit YA (2001) Association of the T102C polymorphism of 5-HT2A receptor gene with aura in migraine. J Neurol Sci 188:99-101

12. Nöthen ErdmannJ, Shimron-Abarbanell D, Proppin P (1994) Identification of genetic variation in the human serotonin 1D receptor gene. Biochem Biophys Res Commun 205:1194-1200

13. Vogt D, Shimron-Abarbanell H, Neidt J, Erdmann S, Cichon TG, Schulze DJ, Muller W, Maier M, Albus M, Borrmann-Hassenbach M, Knapp M, Rietschel P, Propping MM (2000) Nothen. Investigation of the human serotonin $6(5-\mathrm{HT} 6)$ receptor gene in bipolar affective disorder and schizophrenia. Am J Med Genet 96:217-221

14. Mochi M, Cevoli S, Cortelli P, Pierangeli G, Soriani S, Scapoli C, Montagna P (2003) A genetic association study of migraine with dopamine receptor 4, dopamine transporter and dopamine-betahydroxylase genes. Neurol Sci 23:301-305

15. Cevoli S, Mochi M, Scapoli C, Marzocchi N, Pierangeli G, Pini LA, Cortelli P, Montagna P (2006) A genetic association study of dopamine metabolism-related genes and chronic headache with drug abuse. Eur J Neurol 13:1009-1013

16. Monari L, Mochi M, Valentino ML, Arnaldi C, Cortelli P, De Monte A, Pierangeli G, Prologo G, Scapoli C, Soriani S, Montagna P (1997) Searching for migraine gene: exclusion of $290 \mathrm{cM}$ out of the whole human genome. Ital J Neurol Sci 18:277-282

17. Montagna $P$ (2008) The primary headaches: genetics, epigenetics and a behavioural genetic model. J Headache Pain 9:57-69

18. Ogilvie AD, Russell MB, Dhall P, Battersby S, Ulrich V, Smith CA, Goodwin GM, Harmar AJ, Olesen J (1998) Altered allelic distributions of the serotonin transporter gene in migraine without aura and migraine with aura. Cephalalgia 18:23-26

19. Park JW, Han SR, Yang DW, Kim YI, Lee KS (2006) Serotonin transporter protein polymorphism and harm avoidance personality in migraine without aura. Headache 46:991-996

20. Ebstein RP (2006) The molecular genetic architecture of human personality: beyond self-report questionnaires. Mol Psychiatry $11: 427-445$ 